\title{
Editorial \\ Do synovial biopsies help to support evidence for involvement of innate immunity in the immunopathology of Behçet's disease?
} Jan AM van Laar, Jasper H Kappen, Paul LA van Daele and P Martin van Hagen

Department of Internal Medicine, Section of Clinical Immunology \& Department of Immunology, Erasmus University Medical Center, PO Box 2040, 3000 CA Rotterdam, The Netherlands

Corresponding author: Jan AM van Laar, j.vanlaar@erasmusmc.nl

Published: 30 April 2009

This article is online at http://arthritis-research.com/content/11/2/109

Arthritis Research \& Therapy 2009, 11:109 (doi:10.1186/ar2657)

(C) 2009 BioMed Central Ltd

See related research article by Cañete et al., http://arthritis-research.com/content/11/1/R17

\begin{abstract}
Behçet's disease is a complex vasculitis of unknown etiology. Abundant neutrophils suggest the involvement of innate immunity. Cytokines are skewed to the T-helper-1 pattern. Few sterile organs are easily accessible for analysis in Behçet's disease. Cañete and coworkers identify inflamed joints as a feasible model and suggest the involvement of innate immunity in Behçet's disease.
\end{abstract}

In a recent issue of Arthritis Research and Therapy, Cañete and coworkers [1] describe a model for studying the immunopathology of Behçet's disease (BD) by analyzing inflammatory cells, tissue, and cytokines in inflamed joints from BD patients. The etiology of BD is obscure but it is considered to be a complex systemic vasculitis, caused by T-helper-1 (Th1) cytokine skewed neutrophilic and lymphohistiocytic inflammation. Hence, an understanding of how cells and cytokines function in inflamed tissues is important in terms of developing therapeutic interventions [2]. A good example of how mechanistic insight can lead to effective treatment is that $B D$ disease symptoms can be effectively and rapidly reduced by blocking tumor necrosis factor (TNF)- $\alpha$, a key cytokine in $\mathrm{BD}$ [3]. Activation of $\mathrm{BD}$ can be triggered by exogenous factors such as skin damage, introduction of bacterial components, viruses and stress subsequently leading to inflammation [4]. A normal inflammatory response is rapid, non-specific, and self-limiting. It involves a carefully balanced reaction between activated inflammatory cells and an exogenous trigger. In inflammatory disorders such as $\mathrm{BD}$, this response is unbalanced and causes excessive damage to the host. The association of human leukocyte antigen (HLA)-B51 with BD and hyperactive neutrophils stresses the importance of innate immunity in the pathogenesis of the disease [5]. Other factors supporting participation of the innate immune system in BD include the following: prevalence of symptoms in body sites in close contact with the outside environment (skin and mucosa); the presence of hypersensitive $\mathrm{T}$ cells; Toll-like receptor expression in affected cells; and hyperactive neutrophilic and $\mathrm{CD}^{+}{ }^{+} \mathrm{T}$-cell responses to heat shock proteins or bacterial cell wall fragments $[2,4]$. Cytokines that are involved in $\mathrm{BD}$ are largely pro-inflammatory (IL-1 $\beta$, IL-8, IL10 , TNF- $\alpha$, and IFN- $\gamma$ ). Peripheral T cells in BD patients predominantly exhibit a Th1-type pattern of cytokine expression [6].

How does the study of Cañete and coworkers [1] add to the biomechanistic studies that have already been conducted in BD? First, in contrast to most of those studies, the analyses by Cañete and coworkers were conducted in untreated patients. In an uncommon disease such as BD, few studies in naïve patients are reported. In rheumatoid arthritis (RA), for example, early and aggressive treatment is considered mandatory if an optimal therapeutic outcome is to be achieved. It will therefore be of great therapeutic importance to identify possible initiating factors in BD also by testing therapy-naiive patients. This is especially important for the irreversible ophthalmic manifestations of the disease.

Second, it is important that representative tissue is studied. In BD most mechanistic studies are conducted in blood samples; predominantly, testing of circulating cytokines or in vitro peripheral blood mononuclear cells is done. Th1 cytokines are involved, and hyperactive neutrophils and hyper-reactive $T$ cells are held responsible for the symptoms observed [7]. However, BD is an inflammatory disorder involving tissues such as skin, joint, eye, gut, brain, and oral and genital mucosa $[2,4]$. It is therefore mandatory to be sure that observations in blood are representative of biomechanisms at the tissue level.

$\mathrm{BD}=$ Behçet's disease; HLA = human leukocyte antigen; IFN = interferon; IL = interleukin; RA = rheumatoid arthritis; $\mathrm{SF}=$ synovial fluid; SpA = spondyloarthropathy; SPR $=$ skin pathergy reaction; $\mathrm{Th} 1=\mathrm{T}$-helper -1 . 
Mucosal tissue is predominantly involved in BD, and microorganisms from the external environment can readily influence observations in inflammatory cells. On the other hand, those micro-organisms are also capable of stimulating an immune response in BD. Most tissue studies of the pathophysiology of $\mathrm{BD}$ are conducted in skin. One of the unique and diseasespecific features of BD is the occurrence of a positive skin pathergy reaction (SPR), which is observed in 30\% to $75 \%$ of all BD patients [2,4]. Neutrophils and subsequently lymphohistiocytic cells may be observed in sterile lesions following a sterile needle prick [8]. Representing endothelial injury and functioning as leukocyte trafficking factors, cell adhesion molecules (intercellular adhesion molecule-1 and vascular cell adhesion molecule-1) and endothelial growth factor markers such as E-selectin, P-selectin, and endoglin are linked to SPR [9]. Infiltrating cells are mainly of the $\mathrm{HLA}^{-\mathrm{DR}^{+} / \mathrm{CD}^{+} / \mathrm{CD} 4^{+} / \mathrm{CD} 45 \mathrm{RO}^{+} \text {type [10]. Other observa- }}$ tions include mature dendritic cells; monocytes; (regulatory) T cells; elevated levels of IFN- $\gamma$, IL-12-p40 and IL-15; MIP3- $\alpha$ (macrophage inflammatory protein-3 $\alpha$ ); IP-10 (IFN-inducible protein-10); Mig (monokine induced by IFN- $\gamma$ ); iTac (interferon-inducible T cell chemo-attractant); and adhesion molecules [11].

Studies of ocular BD show elevated V $\gamma 9 \mathrm{~V} \delta 2$ (CD4/CD8-) and $\mathrm{CD} 8^{\text {bright }} \mathrm{CD} 6^{+} \mathrm{T}$ cells, which are probably different from those found infiltrating the SPR [12]. Cytokines found to be elevated in ocular fluid from BD patients with active uveitis include IFN- $\gamma$, TNF- $\alpha$, and IL-15 [13]. It must be stressed, however, that aqueous humor is seldom studied because it is difficult to obtain samples; it is only evaluated in intensively and chronically treated BD patients.

In contrast to most of the inflamed organs in BD, the joint is sterile and frequently involved in BD. Cañete and coworkers exploit this readily accessible model, which has not often been studied in BD. Studies of BD arthropathy dating back more than 30 years predominantly revealed neutrophillic infiltration, depending on the stage and treatment of the disease. A more recent study of synovial fluid (SF) from BD patients identified increased levels of chemokines (C-X-C chemokine ligand-9 and -10) related to Th1-directed inflammation [14]. Cañete's group has studied SF extensively in various other arthropathies, such as spondyloarthropathy $(\mathrm{SpA})$ and RA, and comparisons may be made with historical data. Comparing SF samples between SpA and other rheumatic diseases (RA, juvenile SpA, juvenile polyarthritis, and juvenile oligoarthritis) revealed similarities only in terms of the presence of $\mathrm{CD}^{+}, \mathrm{CD}^{+}$, and $\mathrm{CD} 8^{+}$cells [15].

In the study presented Cañete and coworkers [1] conclude that psoriatic arthritis (PsA) resembles BD clinically; a further similarity is the presence of neutrophils in SF from PsA patients. Increased levels of intra-articular $\mathrm{CD} 15^{+}$neutrophils, $\mathrm{CD}^{+} \mathrm{T}$ cells, and perforin were identified in SF from active BD patients relative to SF from patients with PsA. This emphasizes that innate immunity is also involved in early BD and interacts with adaptive immunity, as reflected by the presence of perforin, presumably secreted by $\mathrm{CD}^{+} \mathrm{T}$ cells. It might therefore be of interest to conduct further studies of these naïve $T$ cells and cytokines in sterile $S F$ in order to relate these observations to immunological patterns that have already been described in tissues that are exposed to exogenous factors, or more intensively treated BD patients. These results can then be compared with various other inflammatory diseases in order to obtain greater insight into the immune-related etiology of $\mathrm{BD}$ and to develop more specific, molecular based immunotherapies. Examples may include targeting cytokines (IL-1, IL-10, or IL-6) and use of agents that interfere with lymphocyte action.

\section{Competing interests}

The authors declare that they have no competing interests.

\section{Authors' information}

The authors of this editorial include a $\mathrm{PhD}$ resident $(\mathrm{JK})$ and internist-immunologists (JVL, PVD, and $\mathrm{PVH}$ ), representing the staff of the clinical immunological section of the internal medicine department of the largest Dutch university hospital. Their work concentrates on (auto)immune diseases and immune deficiencies. An outpatient population of more than 110 BD patients represents the largest Dutch population and provides a basis for both immunopathophysiologic, genetic, and therapeutic studies and reports.

\section{References}

1 Cañete JD, Celis R, Noordenbos T, Moll C, Gómez-Puerta JA, Pizcueta P, Palacin A, Tak PP, Sanmartí R, Baeten D: Distinct synovial immunopathology in Behcet disease and psoriatic arthritis. Arthritis Res Ther 2009, 11:R17.

2 Sakane T, Takeno M, Suzuki N, Inaba G: Behçet's disease. $N$ Engl J Med 1999, 341:1284-1291.

3 van Laar JA, Missotten T, van Daele PL, Jamnitski A, Baarsma GS, van Hagen PM: Adalimumab: a new modality for Behçet's disease? Ann Rheum Dis 2007, 66:565-566.

4 Yazici H, Fresko I, Yurdakul S: Behçet's syndrome: disease manifestations, management, and advances in treatment. Nat Clin Pract Rheumatol 2007, 3:148-155.

5 Takeno M, Kariyone A, Yamashita N, Takiguchi M, Mizushima Y, Kaneoka $H$, Sakane T: Excessive function of peripheral blood neutrophils from patients with Behçet's disease and from HLA-B51 transgenic mice. Arthritis Rheum 1995, 38:426-433.

6 Suzuki N, Nara K, Suzuki T: Skewed Th1 responses caused by excessive expression of Txk, a member of the Tec family of tyrosine kinases, in patients with Behcet's disease. Clin Med Res 2006, 4:147-151.

7 Accardo-Palumbo A, Triolo G, Carbone MC, Ferrante A, Ciccia F, Giardina E, Triolo G: Polymorphonuclear leukocyte myeloperoxidase levels in patients with Behçet's disease. Clin Exp Rheumatol 2000, 18:495-498.

8 Ergun T, Gürbüz O, Harvell J, Jorizzo J, White W: The histopathology of pathergy: a chronologic study of skin hyperreactivity in Behçet's disease. Int J Dermatol 1998, 37:929933.

9 Inaloz HS, Evereklioglu C, Unal B, Kirtak N, Eralp A, Inaloz SS: The significance of immunohistochemistry in the skin pathergy reaction of patients with Behçet's syndrome. J Eur Acad Dermatol Venereol 2004, 18:56-61.

10 Gül A, Esin S, Dilsen N, Koniçe M, Wigzell H, Biberfeld P: Immunohistology of skin pathergy reaction in Behçet's disease. Br J Dermatol 1995, 132:901-907.

11 Melikoglu M, Uysal S, Krueger JG, Kaplan G, Gogus F, Yazici H, 
Oliver S: Characterization of the divergent wound-healing responses occurring in the pathergy reaction and normal healthy volunteers. J Immuno/ 2006, 177:6415-6421.

12 Verjans GM, van Hagen PM, van der Kooi A, Osterhaus AD, Baarsma GS: Vgamma9Vdelta2 T cells recovered from eyes of patients with Behçet's disease recognize non-peptide prenyl pyrophosphate antigens. J Neuroimmunol 2002, 130:46-54.

13 Ahn JK, Yu HG, Chung H, Park YG. Intraocular cytokine environment in active Behçet uveitis. Am J Ophthalmol 2006, 142: 429-434.

14 Erdem H, Pay S, Musabak U, Simsek I, Dinc A, Pekel A, Sengul A: Synovial angiostatic non-ELR CXC chemokines in inflammatory arthritides: does CXCL4 designate chronicity of synovitis? Rheumatol Int 2007, 27:969-973.

15 Kruithof E, Van den Bossche V, De Rycke L, Vandooren B, Joos R, Cañete JD, Tak PP, Boots AM, Veys EM, Baeten D: Distinct synovial immunopathologic characteristics of juvenile-onset spondylarthritis and other forms of juvenile idiopathic arthritis. Arthritis Rheum 2006, 54:2594-2604. 